\title{
Analysis of the application of refined management in engineering construction management
}

\author{
Jiao Lili \\ Yunnan College of Business Management, Yunnan, China, 650304
}

Keywords: construction engineering; cost management; quality management; refined management

Abstract: At present, China's construction engineering field shows a trend of high output value, low profit input and small output. The main reason for this problem is the serious shortage of construction engineering management, which makes the enterprise have no method to reduce production cost and input. Therefore, the construction and construction industry should apply the fine management in the development, which is of great importance to the production, cost reduction and efficiency enhancement in the actual construction process. This paper discusses the application of fine management in the construction process management, and elaborates on the economic management application strategy for cost management and quality management in the project production.

\section{Introduction}

Fine management is a new type of management in modern enterprise management concept and management technology. Its main can be embodied in the fine management in practice, emphasis on enterprise management standardization, systematization, digital and information, to help improve the construction enterprise management mode, improve the economic benefit has important significance.

The scientific and rational use of fine management in the concrete implementation stage of construction projects can effectively achieve the objectives of safety, environmental protection, durability and economy of construction projects. Through strengthening project management, construction management, safety construction management and quality supervision. To completely eliminate the many drawbacks of the traditional extensive management of construction enterprises, it is of great significance to realize the goal of building enterprises to improve the economic efficiency of enterprises through engineering construction management ${ }^{[1]}$.

\section{The role of refined management in construction engineering management}

The use of refined management in construction engineering construction management can strengthen the relationship between construction and management, effectively offset the gaps in construction and management of traditional construction engineering construction management, and is of great significance to the achievement of construction project construction goals. The 
application of refined management in construction engineering construction management emphasizes the relationship between enterprise efficiency and employee income, which can effectively improve the mutual trust between engineering management personnel and construction personnel, and mobilize the enthusiasm of construction workers. This is of great significance for improving the construction efficiency and quality control of the concrete implementation stage of the construction projects.

In the practical application, the refined management emphasizes the clear division of labor among the various departments, makes the construction management of the enterprise more comprehensive, scientific and meticulous, and quantifies the power and responsibility of each project management personnel based on the post responsibility system. To avoid the occurrence of power and responsibilities in the construction management of construction projects. Comprehensive implementation of fine management in construction project management can ensure that every construction worker can carry out standardization operations and is of great significance to improve the overall quality and skill level of construction workers. Therefore, economical management can not only effectively improve the construction quality and construction efficiency of construction projects, but also play an important role in improving the safety construction control during the specific implementation stage of the project, helping construction enterprises to maximize economic benefits through refined management ${ }^{[2]}$.

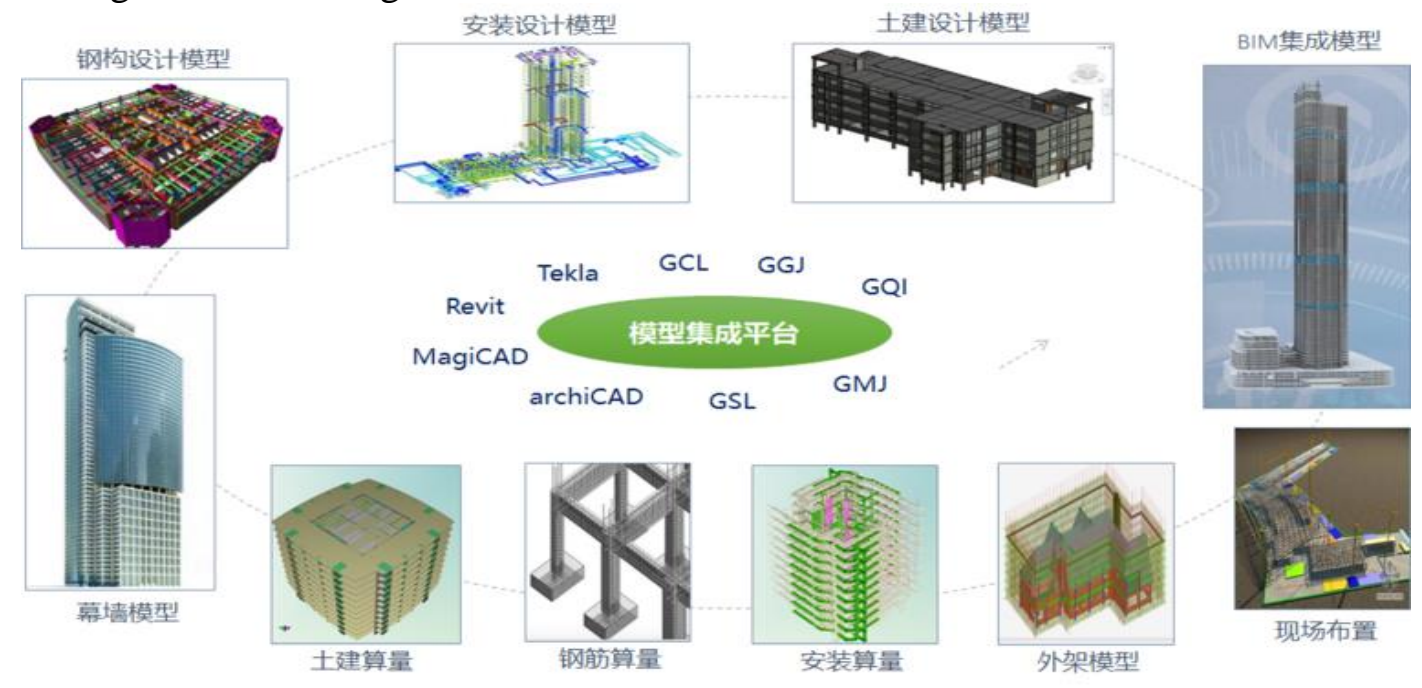

Figure 1: Fine construction management of BIM5D

\section{Application of Fine Management in Construction Engineering Construction Management}

As a scientific and advanced management concept, refined management is very suitable for construction engineering construction management. It can inject more vitality into construction engineering construction management, and make it more standardized and systematic. At present, the fine management is mainly applied in the construction management of construction projects to improve the construction management mechanism of construction enterprises, strengthen the construction quality control of construction enterprises, strengthen the skills training of management personnel and construction personnel, and strengthen the management level of engineering construction materials.

\subsection{Improve the construction management mechanism of construction enterprises}

In the construction preparation stage, the project manager should improve the construction 
management mechanism, taking the improvement of construction management organization and management mechanism as an important content. On the basis of setting up the departments of material management, equipment management, technical management and quality supervision and management, it is necessary to appoint an experienced and highly experienced technical personnel as the chief engineer, who is required to be fully responsible for the construction management of the entire construction project. When applying the refined management, the construction engineering management requires the management personnel to fully realize the importance of contract management, and establish the fund auditing system and contract management rules to ensure that their financial management can meet the requirements of the enterprise and pass the measurement ledger. To strengthen the quality of measurement payment in construction engineering construction management, which plays an important role in improving the financial management work in construction engineering construction management. Construction enterprises should establish and improve various rules and regulations in construction engineering construction management with the help of the chief engineer and supervision unit of the project, so that construction management can avoid any management loopholes in the application of refined management and ensure the construction of construction projects. The standardization and scientific management of management work is of great significance to improve the quality of construction engineering management ${ }^{[3]}$.

\subsection{Strengthening construction quality control of construction enterprises}

The application of refined management in construction engineering construction management emphasizes that enterprises should refine their target responsibilities. Through the implementation of comprehensive planning management to strictly control the construction process, to avoid quality defects in a certain division or sub-project in the construction project, and to avoid the occurrence of illegal operation and random construction events during construction. Through the fine construction management of construction projects to implement the project quality responsibility system, through the signing of the quality responsibility book with the management personnel to achieve the whole process management of the project construction, to ensure that the construction quality of each segment and sub-project can meet the design requirements.

\section{Effective prestressing beam uniformity}

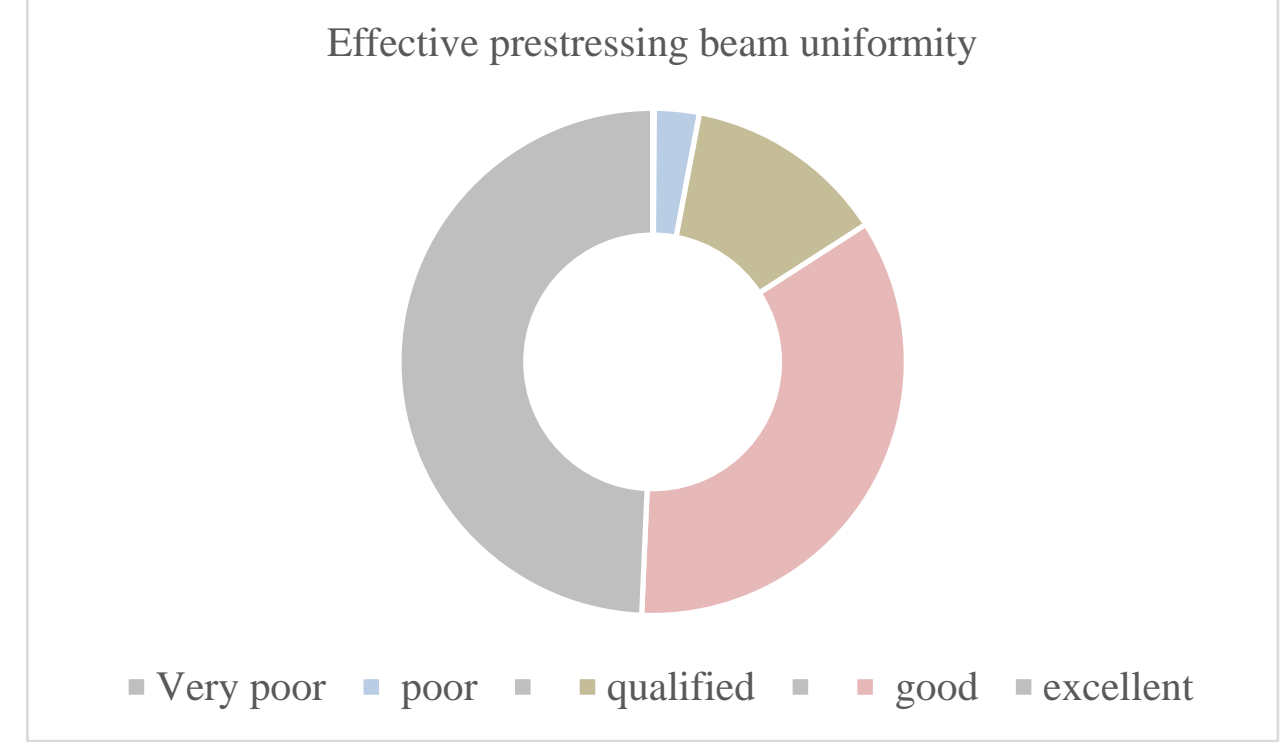

Figure 2: Stress refinement construction and quality technology control in bridge construction engineering 
Construction enterprises must constantly improve the construction of the construction quality assurance system. Under the premise of formulating construction technical specifications and construction process-level construction quality assessment standards, the project construction objectives will be guaranteed through the strengthening of quality supervision and management. And it can help the company to shorten the construction period under the premise of ensuring the construction quality, and avoid the engineering quality problems caused by the construction enterprise in order to shorten the construction period ${ }^{[4]}$.

\subsection{Strengthen the skills training of managers and construction personnel}

The application of refined management in construction engineering construction management helps construction companies realize the importance of corporate training. Only by paying attention to the skills training of construction management personnel and construction personnel can an enterprise effectively improve the construction and construction management level. At the same time, it is also of great significance to improve engineering construction efficiency, construction quality and construction safety. Construction enterprises should conduct regular enterprise training according to the overall quality level of the construction management team, and help construction management personnel to strengthen their understanding of the relevant specifications, standards and operational procedures of construction engineering. Only in this way can construction managers find problems and solve problems in time when they are exposed to new processes, new technologies and new equipment.

\subsection{Strengthen the management level of engineering construction materials}

The traditional construction management of construction enterprises lacks the management of materials. The construction materials management level of most construction enterprises is generally low, which not only seriously weakens the effectiveness of construction engineering management, but also leads to the construction products due to construction. Due to the influence of material quality factors, different quality problems occur. Therefore, in the fine construction management of construction projects, managers are required to strengthen the management of construction materials. The construction engineering construction management personnel shall carry out strict inspection before the new construction materials enter the site to ensure that the construction materials are all products of qualified enterprises with certificate of conformity and factory certificate. After the building materials enter the site, they must be inspected. Only after the parameters meet the corresponding standards, they are allowed to be used in the construction of the building. If unqualified products are found, they should be immediately disposed of by relevant departments to avoid the use of these materials that are not up to standard in construction ${ }^{[5]}$.

\section{Conclusions}

The comprehensive implementation of fine management in the construction management of construction enterprises can completely eliminate the drawbacks brought by the traditional extensive construction management mode, and promote the development of construction management in the direction of standardization, scientific and rationalization. At the same time, managers are required to pay attention to the management of planning, procurement, inspection, construction and acceptance, so as to ensure that construction projects can achieve the objectives of reasonable design, qualified materials and fine construction. It is of great significance to strengthen construction quality, construction efficiency and cost control. 


\section{References}

[1] Wang Yan. Analysis of Fine Construction Management of Construction Engineering[J]. Construction Materials Decoration, 2016(9).

[2] Wang Jiazhong. Exploring the application of refined management in construction engineering construction management[J]. Building Materials Development Orientation: 上, 2015(4):83-84.

[3] Wu Yulong. Exploring the Application of Fine Management in Construction Management of Construction Engineering [J]. City Architecture, 2016(23):100-100.

[4] Zhang Jianguo. Exploring the Application of Fine Management in Construction Management of Construction Engineering[J]. China Real Estate, 2017(15).

[5] Cheng Wei. Exploring the Application of Fine Management in Construction Engineering Construction Management[J]. Science and Technology Innovation, 2017(6): 254-254. 